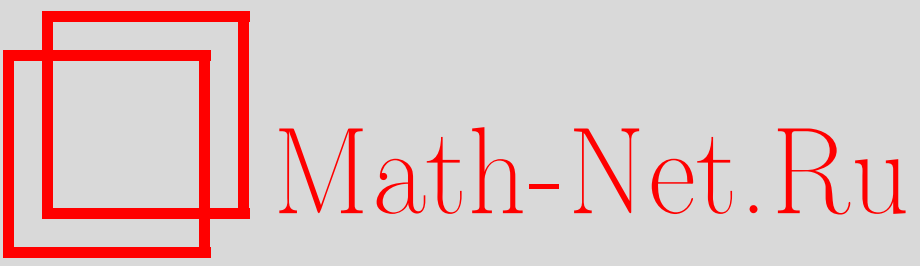

Памяти Михаила Михайловича Глухова, Матем. вопр. криптогр., 2019, том 10, выпуск 1, 5-10

DOI: https://doi.org/10.4213/mvk280

Использование Общероссийского математического портала Math-Net.Ru подразумевает, что вы прочитали и согласны с пользовательским соглашением

http://www.mathnet.ru/rus/agreement

Параметры загрузки:

IP : 35.173 .219 .149

26 апреля 2023 г., $15: 34: 29$ 


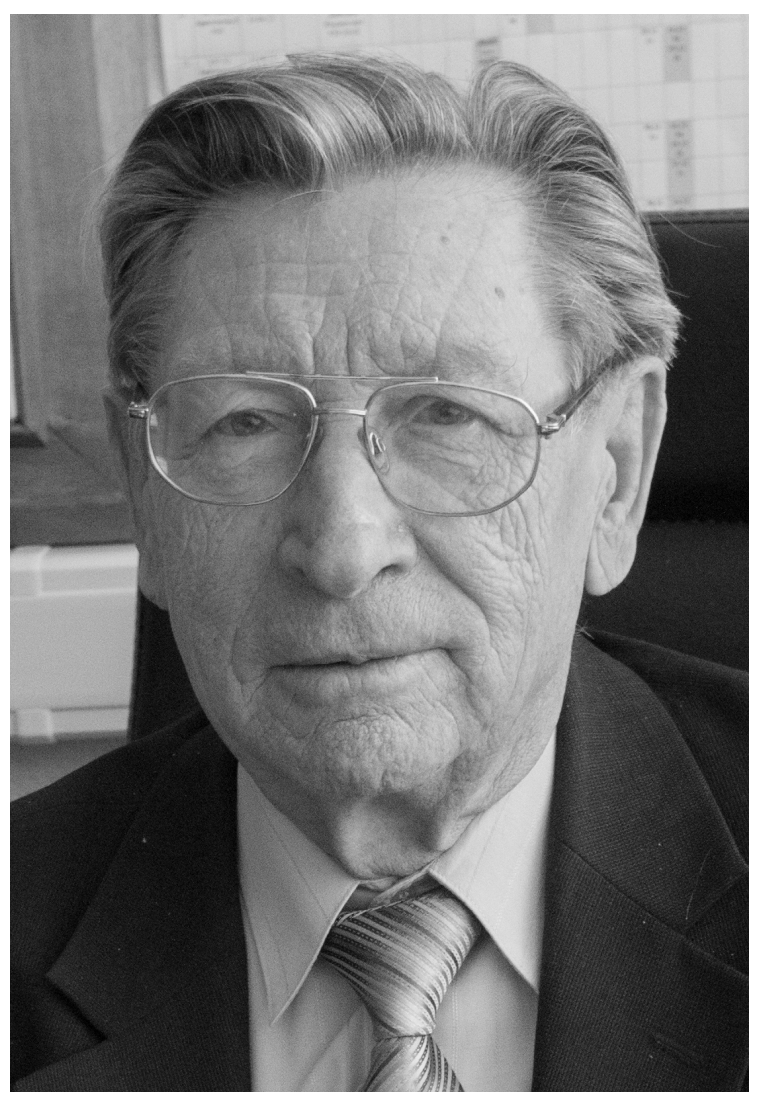

\section{Памяти Михаила Михайловича Глухова} $1930-2018$

9 декабря 2018 года умер Михаил Михайлович Глухов - действительный член Академии криптографии Российской Федерации, заслуженный деятель науки Российской Федерации, профессор, доктор физико-математических наук.

Михаил Михайлович родился 20 ноября 1930 года в селе Тюрнясеве Тельманского (ныне Нурлатского) района Татарской Автономной Советской Социалистической Республики (ныне Республика Татарстан) в семье рабочих.

Его отец - Глухов Михаил Яковлевич - вместе со своим отцом и братьями работал плотником в Тюрнясевском совхозе, участвовал в строительстве хозяйственных объектов и домов для рабочих. В июле 1941 года был мобилизован и погиб в бою с немецко-фашистскими захватчиками в апреле 1942 года под Москвой. 
Из-за трудностей военного времени и необходимости помогать семье Михаил Михайлович окончил среднюю школу в селе Мамыково (в 5 км от села Тюрнясева) только в 1949 году и поступил в двухгодичный Мелекесский учительский институт, который с отличием окончил в 1951 году. С 1951 года по 1954 год он работал учителем математики и физики в Тюрнясевской 7-летней школе и учился заочно в Ульяновском педагогическом институте. В 1954 году сразу после окончания этого института Михаил Михайлович был приглашен на работу в Мелекесский педагогический институт. Здесь он читал лекции и вел практические занятия по нескольким дисциплинам: арифметике, высшей алгебре, теории чисел. В 1958 году Михаил Михайлович поступил в очную аспирантуру Московского государственного педагогического института имени В.И. Ленина. Учась в аспирантуре, преподавал математику в Московском заочном пединституте. По окончании аспирантуры вернулся на работу в Мелекесский педагогический институт, где был назначен деканом физикоматематического факультета.

В 1962 году Михаил Михайлович защитил кандидатскую диссертацию и был приглашен на работу в Москву для проведения исследований в области криптографии. С тех пор его жизнь и научная деятельность были связаны с обеспечением информационной безопасности страны. В 1975 году он защитил докторскую диссертацию. С образованием в 1992 году Академии криптографии Российской Федерации М. М. Глухов был избран ее действительным членом, а в 2005 году - академиком-секретарем отделения математических проблем криптографии; в этой должности он работал до 2016 года.

Круг научных интересов Михаила Михайловича охватывал широкий спектр вопросов в области математической логики и конечных алгебраических систем. Полный список его научных трудов содержит более 150 наименований. Последняя статья Михаила Михайловича опубликована в этом выпуске журнала. Он получил важные результаты по универсальным алгебрам, конечным полям, кольцам и их преобразованиям.

Наибольший вклад Михаил Михайлович внес в развитие теории групп, квазигрупп и луп (неассоциативных групп) и их применений в криптографии. В частности, он ввел и исследовал параметры, широко используемые при анализе и синтезе современных систем засекречивания и связанные с покрытием конечной группы заданной системой образующих: длину, ширину и глубину покрытия. Для ряда основных систем образующих симметрической группы им были получены оценки длин покрытия и мощностей покрывающих слоев; было найдено точное значение показателя $r$-транзитивности множеств раундовых преобразований шифрсистемы AES. 
Одним из первых в отечественной криптографии Михаил Михайлович начал изучать возможности использования линейных рекуррентных последовательностей над примарными непростыми кольцами вычетов и вывел критерии максимальности периодов таких рекуррент. Он ввел понятие функций $k$-значной логики итеративного типа и провел первые исследования свойств таких функций. Обобщая известную теорему А. А. Маркова, Михаил Михайлович получил полное описание множества инъективных отображений слов в одном алфавите в слова в другом алфавите, не размножающих искажений типов замены букв, пропусков букв, вставки букв и всевозможных комбинаций таких искажений.

На протяжении 20 лет (с 1973 г. по 1993 г.) Михаил Михайлович возглавлял кафедру математики технического факультета Высшей школы КГБ СССР. Имея профессиональное педагогическое образование, он заложил основы обучения базовым математическим дисциплинам в области информационной безопасности, а также привлек на эту кафедру лучших специалистов. Под его руководством защищено 14 кандидатских диссертаций, трое его учеников стали докторами наук. Научная школа, возглавляемая М.М.Глуховым, объединяла ведущих ученых и неоднократно удостаивалась гранта Президента Российской Федерации для поддержки ведущих научных школ Российской Федерации.

Михаил Михайлович - автор нескольких базовых учебников и учебных пособий по алгебре, аналитической геометрии, математической логике, теории дискретных функций и теории алгоритмов, теоретико-числовым методам в криптографии, теории представлений групп. Эти книги учитывают потребности будущих специалистов по защите информации, способствуют активному применению полученных знаний на практике и полезны для широкого круга читателей: от студентов до аспирантов и научных работников. Они активно используются вузами, осуществляющими образование в области информационной безопасности.

За успехи в научной и педагогической деятельности Михаил Михайлович награжден орденом «Знак почета» в 1986 году и орденом Почета в 2010 году. В 1997 году ему присвоено звание «Заслуженный деятель науки Российской Федерации».

Все, кто знал Михаила Михайловича, запомнят его как высокоэрудированного ученого, доброжелательного и общительного человека.

Редакционная коллегия журнала

2019, T. 10, № 1, C. 5-10 


\section{Избранные публикации М.М. Глухова}

1. Глухов М. М., Елизаров В. П., Нечаев А. А., Алгебра, 1-е изд., в 2 m., М. : Гелиос АРВ, 2003, 416 с.; 2-е изд., СПб. : Лань, 2015, 608 с.

2. Глухов М. М., Алгебра и геометрия, М.: Гелиос АРВ, 2011, 392 с.

3. Глухов М.М., Круглов И.А., Пичкур А.Б., Черемушкин А.В., Введение в теоретикочисловые методы криптографии, СПб.: Лань, 2011, 40 с.

4. Глухов М. М., Шишков А. Б., Математическая логика. Дискретные функции. Теория алгоритмов, СПб. : Лань, 2012, 416 с.

5. Глухов М.М., Круглов И. А., Элементы теории обыкновенных представлений и характеров конечных групп с приложениями в криптографии, СПб. : Лань, 2015, 176 с.

6. Глухов М.М., “К проблеме изоморфизма структур”, Доклады АН СССР, 132 :2 (1960), 254-256.

7. Глухов М.М., “К теоретико-структурной теореме типа теоремы Грушко”, Доклады АН СCCP, $138: 5$ (1961), 994-997.

8. Гварамия А.А., Глухов М.М., “Об алгоритмических проблемах для некоторых классов квазигрупп”, Доклады АН СССР, 177:1 (1967), 14-16.

9. Глухов М. М., Стеллецкий И. В., Фофанова Т. С., “Теория структур”, Итоги науки. Сер. Мат. Алгебра. Топол. Геом., М. : ВИНИТИ, 1970, 101-154.

10. Глухов М.М., “О свободных произведениях и алгоритмических проблемах в $R$-многообразиях универсальных алгебр”, Доклады АН СССР, 193 :3 (1970), 514-517.

11. Глухов М.М., “Свободные разложения и алгоритмические проблемы в $R$-многообразиях универсальных алгебр”, Математический сборник, 85 (127):3(7) (1971), 307-338.

12. Глухов М. М., Ларин С. В., “Абелевы и метабелевы группы с регулярными автоморфизмами и полуавтоморфизмами”, Математические заметки, 12 :6 (1972), 727-738.

13. Глухов М.М., Тимофеенко Г.В., “Группа автоморфизмов конечно-определенных квазигрупп”, Математические заметки, 37:5 (1985), 617-626.

14. Глухов М.М., “Об $\alpha$-замкнутых классах и $\alpha$-полных системах функций $k$-значной логики”, Дискретная математика, $1: 1$ (1989), 16-21.

15. Глухов М. М., “T -разбиения квазигрупп и групп”, Дискретная математика, 4:3 (1992), $47-56$.

16. Глухов М.М., “О классификации квазигрупп по свойствам их $T$-разбиений”, Дискретная математика, 4:4 (1992), 3-11.

17. Глухов М.М., Расулов Х. С., “Особые $C$-эквивалентности конечных односторонне обратимых квазигрупп”, Дискретная математика, $6: 3$ (1994), 3-17.

18. Глухов М. М., "Нижние оценки сумм характеров от многочленов над конечными полями”, Дискретная математика, $6: 3$ (1994), 136-142. 
19. Глухов М.М., “О числовых параметрах, связанных с заданием конечных групп системами образующих элементов”, Труды по дискретной математике, 1, 1997, 43-66.

20. Глухов М.М., “О некоторых алгоритмических проблемах и свободных произведениях в $R$-многообразиях линейных $\Omega$-алгебр”, Фундаментальная и прикладная математика, $3: 2$ (1997), 373-397.

21. Бабаш А. В., Глухов М. М., Шанкин Г. П., “О преобразованиях множества слов в конечном алфавите, не размножающих искажений”, Дискретная математика, 9:3 (1997), 3-19.

22. Глухов М.М., “Инъективные отображения слов, не размножающие искажений типа пропусков букв”, Дискретная математика, 11 :2 (1999), 20-39.

23. Глухов М.М., “О 2-транзитивных произведениях регулярных групп подстановок”, Труды по дискретной математике, 3, 2000, 37-52.

24. Глухов М.М., “Инъективные отображения слов, не размножающие искажений”, Труды по дискретной математике, 4, 2001, 17-32.

25. Глухов М.М., “О сложности решения систем линейных уравнений над конечными коммутативными цепными кольцами”, Труды по дискретной математике, 6, 2002, 14-30.

26. Глухов М.М., “Исследование колец вычетов биквадратичных расширений кольца целых чисел и схемы с открытым ключом”, Труды по дискретной математике, 7, 2003, 31-55.

27. Глухов М. М., “Использование колец вычетов целых алгебраических чисел для построения криптографических систем с открытым ключом”, Труды по дискретной математике, 10 , 2007, 47-72.

28. Глухов М.М., “О применениях квазигрупп в криптографии”, Прикладная дискретная математика, № 2(2) (2008), 28-32.

29. Глухов М. М., “Об использовании групп классов идеалов квадратичных полей для построения криптографических систем с открытым ключом”, Математические вопросы криптографии, $1: 1$ (2010), 23-54.

30. Глухов М. М., “К анализу некоторых систем открытого распределения ключей, основанных на неабелевых группах", Математические вопросы криптографии, 1 :4 (2010), 5-22.

31. Глухов М.М., “О рассеивающих линейных преобразованиях для блочных шифрсистем”, Математические вопросы криптографии, 2 :2 (2011), 5-39.

32. Глухов М. М., “О методах построения систем ортогональных квазигрупп с использованием групп”, Математические вопросы криптографии, 2 :4 (2011), 5-24.

33. Глухов М.М., Закревский П.Н., “О коэффициентах аддитивности и аффинности дискретных функций”, Дискретная математика, $24: 1$ (2012), 30-47.

34. Глухов М. М., “О матрицах переходов разностей при использовании некоторых модулярных групп”, Математические вопросы криптографии, № 4 (2013), 27-47.

35. Глухов М. М., “О мультипликативных группах свободных и свободных коммутативных квазигрупп”, Фундаментальная и прикладная математика, $20: 1$ (2015), 23-37. 
36. Глухов М.М., “О проблеме равенства слов в свободных квазигруппах многообразий квазигрупп, изотопных группам”, Фундаментальная и прикладная математика, 20:1 (2015), $39-55$.

37. Глухов М. М., “О приближении дискретных функций линейными функциями”, Математические вопросы криптографии, $7: 4$ (2016), 29-50.

38. Глухов М.М., “О 2-транзитивных произведениях трех регулярных групп подстановок конечного поля”, Математические вопросы криптографии, 10:1 (2019), 9-24. 